\title{
Zn (II) and Cu (II) Halide Complexes of Poly(propylene amine) Dendrimer Analysed by Infrared and Raman Spectroscopies
}

\author{
Ivo Grabchev, ${ }^{1,2}$ Ismail Hakki Boyaci, ${ }^{3}$ Ugur Tamer, ${ }^{4}$ and Ivan Petkov ${ }^{5}$ \\ ${ }^{1}$ Sofia University "St. Kliment Ohridski", Faculty of Medicine, 1407 Sofia, Bulgaria \\ ${ }^{2}$ Chemistry Department, Faculty of Science, King Abdulaziz University, Jeddah 21589, Saudi Arabia \\ ${ }^{3}$ Hacettepe University, Faculty of Engineering, Department of Food Engineering, Beytepe Campus, 06800 Ankara, Turkey \\ ${ }^{4}$ Department of Analytical Chemistry, Faculty of Pharmacy, Gazi University, 06330 Ankara, Turkey \\ ${ }^{5}$ Sofia University "St. Kliment Ohridski", Faculty of Chemistry and Pharmacy, 1153 Sofia, Bulgaria \\ Correspondence should be addressed to Ivo Grabchev; i.grabchev@chem.uni-sofia.bg
}

Received 12 April 2013; Revised 13 June 2013; Accepted 14 June 2013

Academic Editor: Alfonso Castiñeiras

Copyright (c) 2013 Ivo Grabchev et al. This is an open access article distributed under the Creative Commons Attribution License, which permits unrestricted use, distribution, and reproduction in any medium, provided the original work is properly cited.

Two nondestructive and complementary spectral methods as infrared and Raman spectroscopies have been used for characterizations of poly(propylene amine) dendrimers comprising 1,8-naphthalimide units in the dendrimer periphery and their metal complexes with $\mathrm{Cu}^{2+}$ at $\mathrm{Zn}^{2+}$ ions.

\section{Introduction}

Poly(propylene amine) (PPA) is a new class of commercial dendrimers possessing tertiary amino groups in the core and terminal primary amino groups in the dendrimer periphery [1]. Their luminescent characteristics can be customized by modifying the periphery with different fluorophores. We have extensively studied the dendrimer modifications with 1,8naphthalimides in response to the needs of vanguard sensors for preventing environment pollution [2-7].

Different spectral methods and techniques as UV-vis and fluorescence, FTIR and Raman, NMR, AFM, and EPR are used for identification and characterization of dendrimers [8]. Some of these methods used for studying the vibrations of atoms in dendrimer molecules are infrared and Raman spectroscopies. The difference between both of spectral methods lies in the fact that while in infrared spectroscopy are important oscillations, changing dipole moment, in the Raman spectroscopy is characteristic the change of polarizability of molecules. The main advantage of Raman spectroscopy compared to Infrared spectroscopy is the small water absorption, which is offered especially for biological and medical investigations without further sample preparations. Surface-enhanced Raman spectroscopy (SERS) takes the advantage of strongly increased Raman scattering signal generated by local field enhancement near metallic nanostructures [9]. An example exploits the local plasmon modes at the interface between two metal nanoparticles. A key requirement to achieve such detection is the placement of the analyte close to more than one plasmonic surface [10]. To date, isotropic and anisotropic metallic nanoparticles such as gold and silver have been promising SERS substrates because of their tunable optical properties, controllable particle size distribution, easy synthesis procedure, long-term stability, and high biocompatibility [11]. On the other hand, the infrared spectroscopy is more informative in the case of the investigations of polar functional groups in organic compounds. This means that these spectral methods are complementary and appropriate for researching the structure of organic molecules [12].

In this paper we present Raman and infrared spectral analyses on $\mathrm{Zn}$ (II) and $\mathrm{Cu}$ (II) halide complexes of poly(propylene amine) dendrimers of first and second generations, comprising 1,8-naphthalimide units in the dendrimer periphery. Their spectral characteristics have been investigated in solid state and in DMSO solution in the presence of Ag nanoparticles. 
<smiles>O=C1c2cccc3cccc(c23)C(=O)N1CCCN(CCCCN(CCCN1C(=O)c2cccc3cccc(c23)C1=O)CCCN1C(=O)c2cccc3cccc(c23)C1=O)CCCN1C(=O)c2cccc3cccc(c23)C1=O</smiles>

PPA1

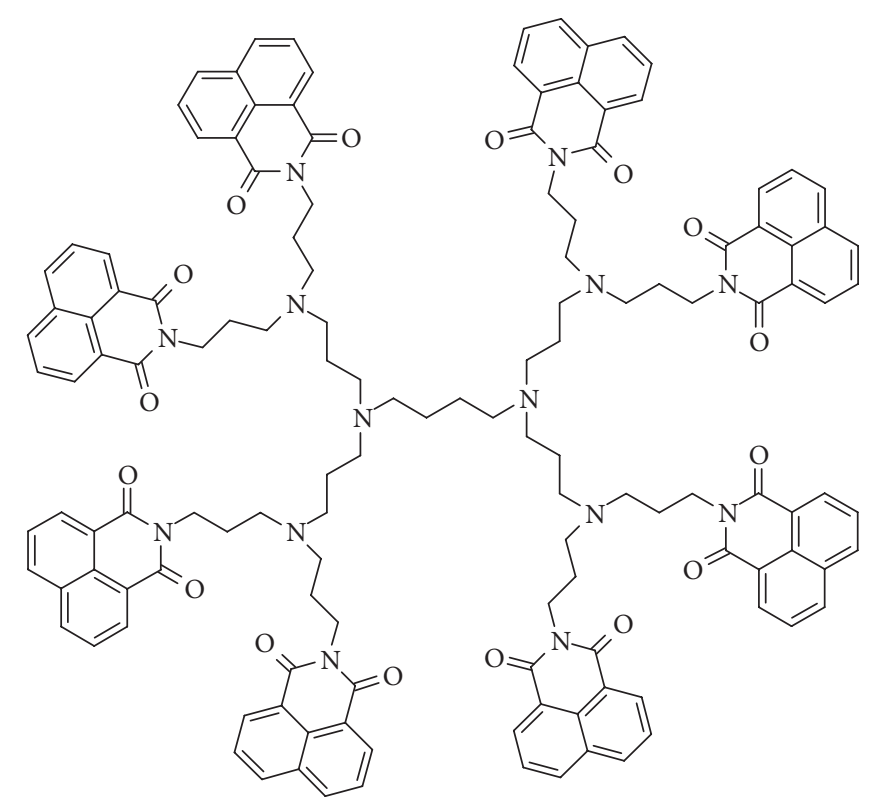

PPA2

SCHEMe 1: Chemical structure of dendrimers PPA1 and PPA2.

\section{Experimental}

2.1. Materials. First and second generations PPA dendrimers modified with 1,8-naphthalimide derivatives have the structures shown in Scheme 1. Their synthesis and metal complexes preparation have been published recently $[6,13]$.

2.2. Synthesis of Ag Nanoparticles. Before preparation of the colloids, the whole glassware was washed with aqua regia and rinsed with deionized water. Hydroxylamine reduced silver nanoparticles were prepared as reported by Leopold and Lendl [14]. Briefly, hydroxylamine hydrochloride $(1.67 \times$ $\left.10^{-3} \mathrm{M}\right)$ and $\mathrm{NaOH}\left(3.33 \times 10^{-3} \mathrm{M}\right)$ were dissolved in $90 \mathrm{~mL}$ deionized water. To the basic solution, $10 \mathrm{~mL} \operatorname{AgNO}_{3}(1 \times$ $\left.10^{-2} \mathrm{M}\right)$ was added dropwise, stirred for 30 minutes, and stored in dark place. The concentration of the ultimate silver colloid solution was assumed as $1 \mathrm{X}$. The study was carried out to find out the optimum concentration of silver colloid. 2.5 times concentrated solution gave the best signal enhancement for SERS measurements, and this concentration was used for all SERS measurements in the study.

2.3. Instrumentation. DeltaNu Examiner Raman Microscopy system with a $785 \mathrm{~nm}$ laser source, a motorized microscope stage sample holder, and a cooled charge-coupled device $\left(\mathrm{CCD}\right.$, at $\left.0^{\circ} \mathrm{C}\right)$ detector were used. Instrument parameters were as follows: $20 \mathrm{x}$ objective, $30 \mu \mathrm{m}$ laser spot size, $150 \mathrm{~mW}$ laser power, and $30 \mathrm{~s}$ acquisition time. Baseline correction was performed for all of the measurements. In solid sample measurement, sample was placed on a glace slide and Raman spectrum of the sample was obtained with micro-Raman system. In liquid sample measurement, sample was dissolved in DMSO and then diluted with Milli-Q quality water $(18 \mathrm{M} \Omega \mathrm{cm})$ up to $10^{-4} \mathrm{M}$ concentration. After that $50 \mu \mathrm{L}$ sample was mixed with $50 \mu \mathrm{L} 10 \mathrm{X}$ Ag nanoparticles in Raman cuvette, and Raman spectrum of the mixture was obtained in the range of $200-2000 \mathrm{~cm}^{-1}$ at a resolution of $2 \mathrm{~cm}^{-1}$ with constant measurement parameters. Infrared analysis of both dendrimers and their complexes with metal ions was carried out using an infrared Fourier transform spectrometer (IRAffinity-1) with the diffuse-reflectance attachment (MIRacle Attenuated Total Reflectance Attachment) at a $2 \mathrm{~cm}^{-1}$ resolution.

\section{Results and Discussion}

Stretching and deformation vibrations of the main functions in the infrared region of PPA dendrimers from first and second generations modified with 1,8-naphthalimides and their metal complexes are summarised in Table 1.

The carbonyl groups from the imide structure give rise to both of the frequency bands of $\mathrm{C}=\mathrm{O}$ absorption [15]. The IR spectrum of the initial dendrimers PPA1 and PPA2 possesses very similar intensive bands at $1697 \mathrm{~cm}^{-1}, 1654 \mathrm{~cm}^{-1}$, $1696 \mathrm{~cm}^{-1}$, and $1655 \mathrm{~cm}^{-1}$. The characteristic bands for the $\mathrm{C}-\mathrm{N}$ bonds due to the tertiary amino group from aliphatic dendrimer structure and $\mathrm{C}-\mathrm{N}-\mathrm{C}$ imidic structure from the 1,8 -naphthalimide are at $1354-1340 \mathrm{~cm}^{-1}, 1242-1232 \mathrm{~cm}^{-1}$, and $1207-1174 \mathrm{~cm}^{-1}$.

The aromatic naphthalene ring from the 1,8naphthalimide units is responsible for the absorptions due to the $\mathrm{C}-\mathrm{H}$ stretching vibrations at $3063-3072 \mathrm{~cm}^{-1}$. The characteristic $\mathrm{C}-\mathrm{H}$ out-of-plane deformation vibrations 
TABLE 1: Experimental infrared wavenumbers of dendrimers in $\mathrm{cm}^{-1}$.

\begin{tabular}{|c|c|c|c|c|c|c|c|c|}
\hline & $v_{\mathrm{C}-\mathrm{H}}$ arom & $v_{\mathrm{CH}_{2}}$ & $v_{\mathrm{C}=\mathrm{O}}^{\mathrm{AS}}$ & $v_{\mathrm{C}=\mathrm{O}}^{\mathrm{S}}$ & $\nu_{\mathrm{C}=\mathrm{C}}$ arom & $v_{\mathrm{CH}_{2}}$ & $v_{\mathrm{C}-\mathrm{N}}$ & $\delta_{\mathrm{C}-\mathrm{H}}$ arom \\
\hline PPA1 & 3068 & $\begin{array}{l}2958 \\
2874\end{array}$ & 1697 & 1655 & $\begin{array}{l}1624 \\
1589\end{array}$ & 1440 & $\begin{array}{l}1340 \\
1232 \\
1194\end{array}$ & $\begin{array}{l}845 \\
777\end{array}$ \\
\hline $\mathrm{PPA} 1 / \mathrm{Cu}^{2+}$ & 3065 & $\begin{array}{l}2966 \\
2881\end{array}$ & 1690 & 1647 & $\begin{array}{l}1617 \\
1582 \\
1455\end{array}$ & 1432 & $\begin{array}{l}1335 \\
1285 \\
1230 \\
1184\end{array}$ & $\begin{array}{l}842 \\
775\end{array}$ \\
\hline $\mathrm{PPA} 1 / \mathrm{Zn}^{2+}$ & 3072 & $\begin{array}{l}2960 \\
2793\end{array}$ & 1694 & 1648 & $\begin{array}{l}1620 \\
1586 \\
1452\end{array}$ & 1434 & $\begin{array}{l}1341 \\
1232 \\
1191\end{array}$ & $\begin{array}{l}843 \\
776\end{array}$ \\
\hline PPA2 & 3068 & $\begin{array}{l}2958 \\
2874\end{array}$ & 1696 & 1654 & $\begin{array}{l}1624 \\
1587\end{array}$ & 1437 & $\begin{array}{l}1342 \\
1232 \\
1174\end{array}$ & $\begin{array}{l}874 \\
777\end{array}$ \\
\hline $\mathrm{PPA} 2 / \mathrm{Cu}^{2+}$ & 3068 & $\begin{array}{l}2953 \\
2870\end{array}$ & 1691 & 1646 & $\begin{array}{l}1620 \\
1583 \\
1451\end{array}$ & 1432 & $\begin{array}{l}1340 \\
1228 \\
1178\end{array}$ & $\begin{array}{l}842 \\
775\end{array}$ \\
\hline $\mathrm{PPA} 2 / \mathrm{Zn}^{2+}$ & 3063 & $\begin{array}{l}2958 \\
2832\end{array}$ & 1692 & 1647 & $\begin{array}{l}1618 \\
1584 \\
1455\end{array}$ & 1432 & $\begin{array}{l}1338 \\
1230 \\
1184\end{array}$ & $\begin{array}{l}842 \\
775\end{array}$ \\
\hline
\end{tabular}

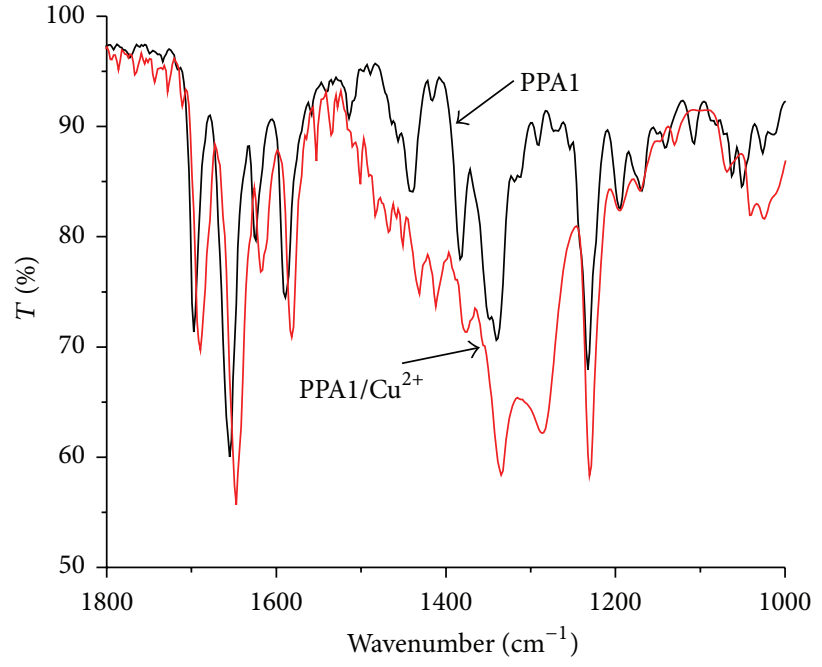

(a)

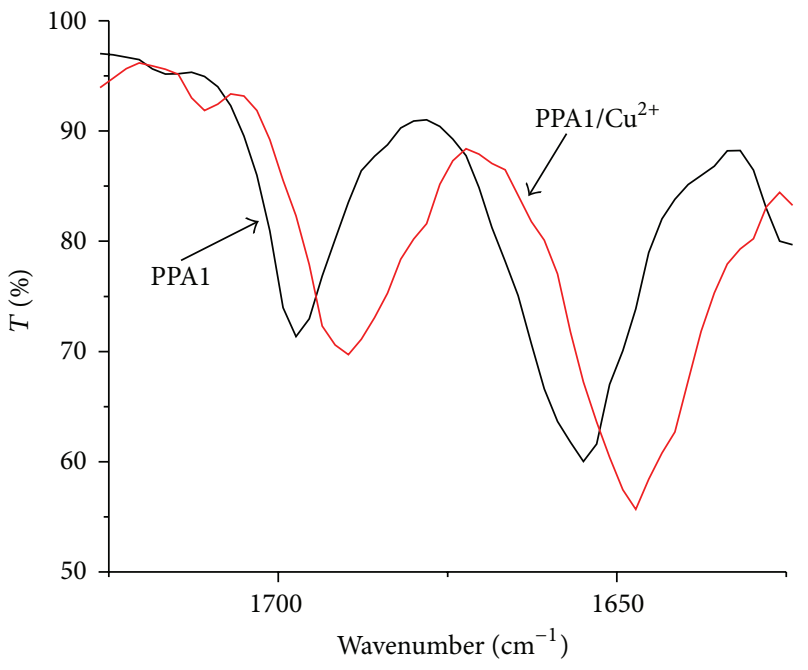

(b)

Figure 1: Infrared spectra of PPA1 dendrimer and PPA1/ $\mathrm{Cu}^{2+}$ complex.

of the aromatic naphthalene rings are at $775-779 \mathrm{~cm}^{-1}$ and $843-874 \mathrm{~cm}^{-1}$.

PPA dendrimers under study comprise also aliphatic methylene $\left(-\mathrm{CH}_{2}-\right)$ groups in the dendrimer core. The absorption at $2832-2881 \mathrm{~cm}^{-1}$ for the asymmetric stretching vibrations and at $2953-2966 \mathrm{~cm}^{-1}$ for the symmetric stretching vibrations indicates the presence of hydrogen atom bonded to $\mathrm{sp}^{3}$ hybridized carbon atoms $(\mathrm{C}-\mathrm{H})$.

Figure 1 shows the IR spectra of PPA1 and its metal complex PPA1 $/ \mathrm{Cu}^{2+}$ given as a comparison. It is seen that the absorption bends in the region $1500-1250 \mathrm{~cm}^{-1}$ are different (Figure 1(a)). A new intensive band at $1290 \mathrm{~cm}^{-1}$ was observed in the spectra of PPA1/ $\mathrm{Cu}^{2+}$ complex which probably is due to the metal ions complex formation. The characteristic $\mathrm{C}-\mathrm{H}$ out-of-plane deformation vibrations of the aromatic naphthalene rings of PPA1 and PPA1/Cu ${ }^{2+}$ at the region $850-750 \mathrm{~cm}^{-1}$ are also very close. In the region where absorb $\mathrm{C}=\mathrm{O}$ groups from the 1,8-naphthalimide structure $\left(1620-1720 \mathrm{~cm}^{-1}\right)$ the difference is $6-8 \mathrm{~cm}^{-1}$ (Figure 1(b)) which can be explained by the possible metal ions coordination with $\mathrm{C}=\mathrm{O}$ groups. The same results have been obtained in the case of PPA2 dendrimer and its metal complex. In Figure 2 the infrared spectra of PPA 2 and PPA2 $/ \mathrm{Zn}^{2+}$ are plotted as an example. It is seen that in the region where absorb both carbonyl groups the difference is the same as that in the case of PPA1 dendrimer. The difference has been also observed and in the spectral region $\left(1200-1400 \mathrm{~cm}^{-1}\right)$ where absorb tertiary amine and amide groups. 


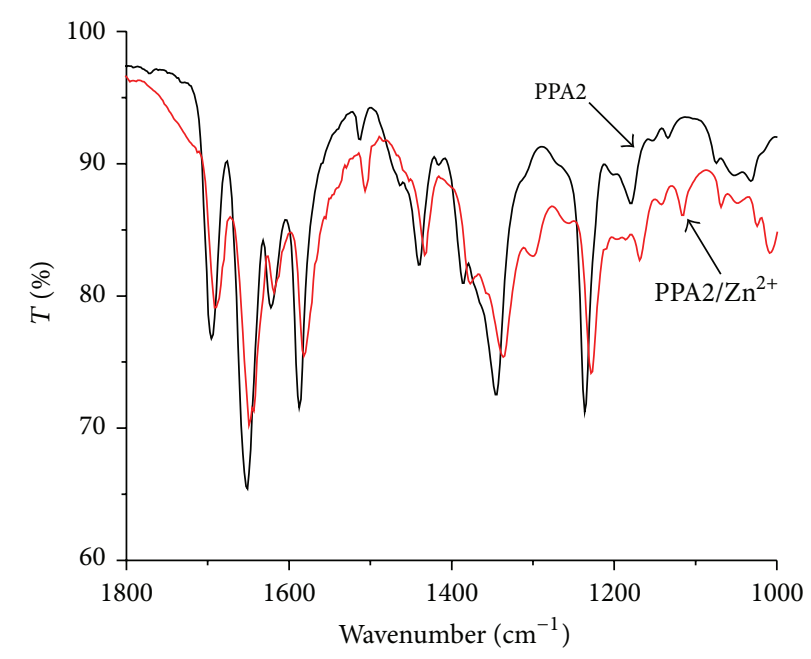

FIGURE 2: Infrared spectra of PPA2 dendrimer and PPA2/Zn ${ }^{2+}$ complex.

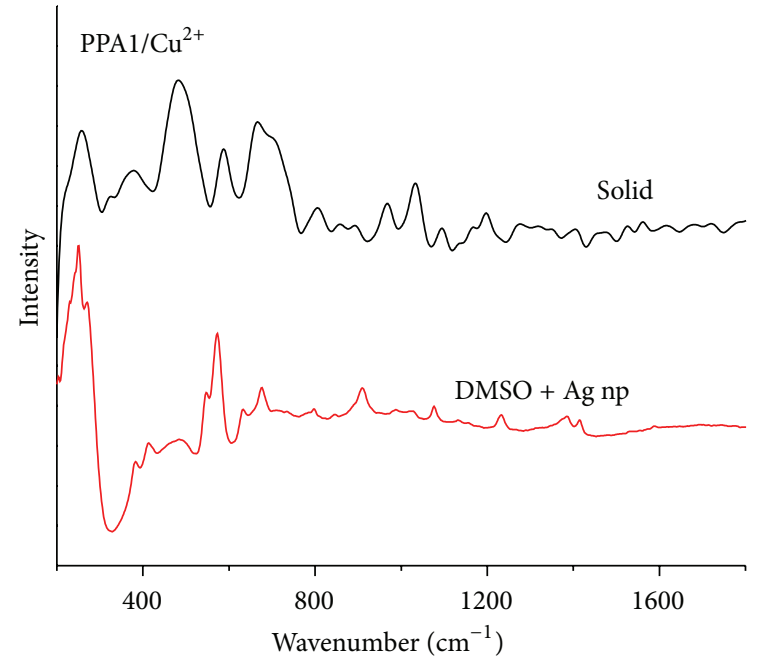

(a)

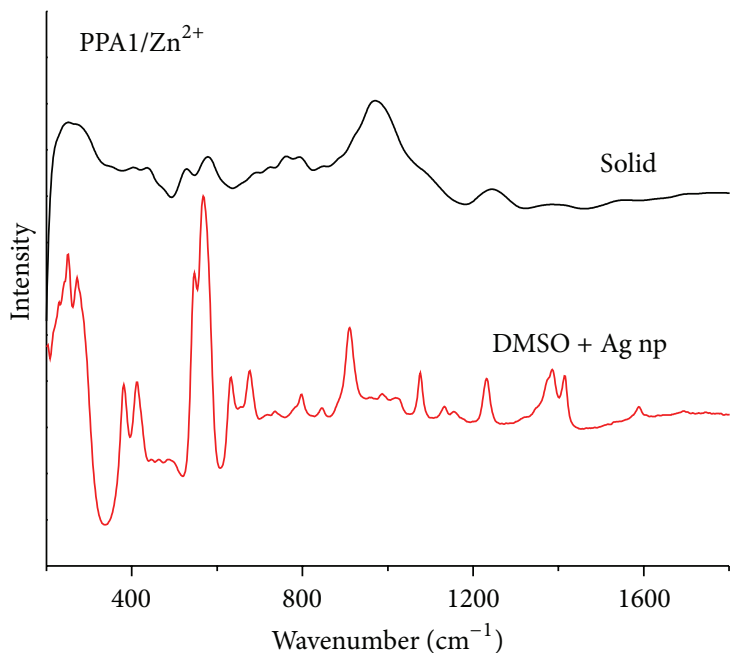

(b)

FIgURE 3: Raman spectra of PPA1 dendrimer complex in solid state and in DMSO solutions in the presence of silver nanoparticles.

When Raman active molecules are located near nanoparticles surface within the nanoparticles assembly, Raman signal intensities are substantially enhanced due to formation of hotspot. Metal nanoparticles have been used as the substrates for surface-enhanced Raman scattering (SERS) due to the enhancement mechanisms. The first mechanism has a chemical origin, which is due to the formation of a charge-transfer complex between the surface and the analyte molecules. The second mechanism can be attributed to the enhancement in electromagnetic field as a result of strong surface plasmon resonance of metal nanoparticle. The second mechanism amplifies the incident laser field and the scattered Raman field through their interaction with particle surface. The Raman scattering enhancement is attributed to plasmonic coupling between nanoparticles in close proximity, which results in local electromagnetic field enhancement on hotspots [16].

One of the major research topics is the development of nanoparticle assemblies which are capable of monitoring
SERS activity for application in environmental monitoring, diagnosis, and biodetection [17]. The analytical applications of Raman are limited due to low Raman cross-section of the analyte, which is often the case in inorganic metal species. However, SERS is a powerful spectroscopy technique for the monitoring spectral changes after interactions between metal cations and nanoparticles.

The metal ions complexes of dendrimers PPA1 and PPA2 have been analyzed by Raman spectroscopy in the region $200-2000 \mathrm{~cm}^{-1}$ in solid state and in DMSO. Respective Raman spectra of the PPA/ $/ \mathrm{Cu}^{2+}$ and PPA/ $/ \mathrm{Zn}^{2+}$ are plotted in Figures 3, 4, and 5. In DMSO solution, silver nanoparticles have been used for better Raman signal enhancement, if compared to this investigated in solid state. The silver nanoparticles may aggregate in the presence of DMSO after the addition of metal complexes. This process may potentially affect the SERS signal. Therefore the experimental conditions 


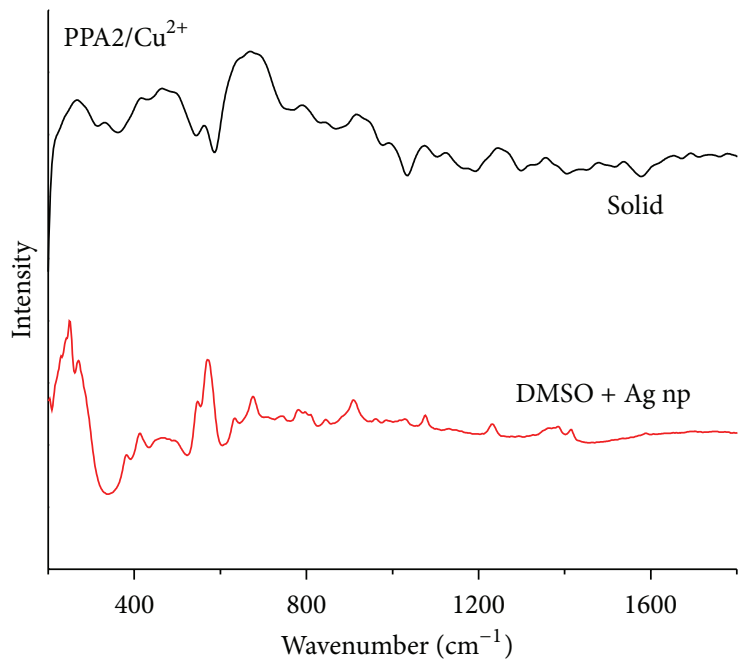

(a)

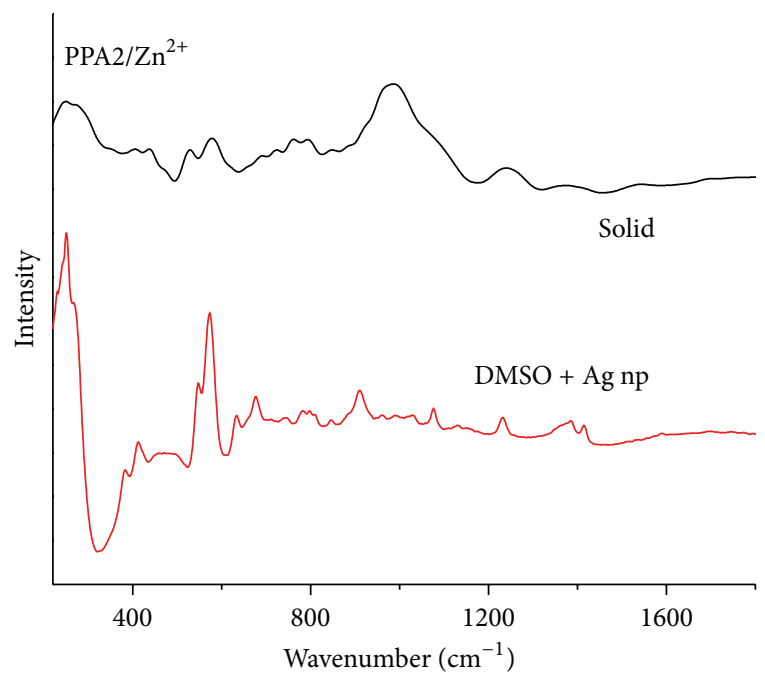

(b)

FIGURE 4: Raman spectra of PPA2 dendrimer complex in solid state and in DMSO solutions in the presence of silver nanoparticles.

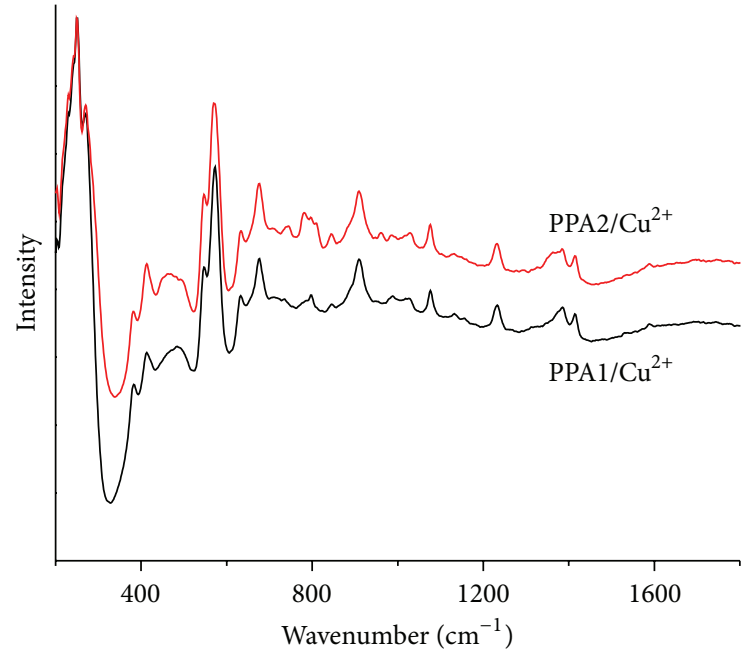

Figure 5: Raman spectra of PPA1/Cu ${ }^{2+}$ and PPA2/ $\mathrm{Cu}^{2+}$ complex in DMSO solutions in the presence of silver nanoparticles.

such as the concentrations of silver nanoparticles and the type of solvent molecule are very important in order to get SERS signaling as much as possible. From the spectra in solutions and in solid state, it is seen that there are some changes in bands and lines intensity in the Raman spectra of both of the dendrimer complexes.

The strong bands of the Raman spectra of both of the dendrimer generations at $570-577 \mathrm{~cm}^{-1}$ are characteristics for $\mathrm{C}-\mathrm{C}-\mathrm{C}$ in-plane aromatic vibration. The bands at 764$806 \mathrm{~cm}^{-1}$ can be assigned for $\mathrm{C}-\mathrm{H}$ out-of-plane bending while those at $1074-1096 \mathrm{~cm}^{-1}$ are for $\mathrm{C}-\mathrm{H}$ in-plane bending. The characteristic bands for the $\mathrm{C}-\mathrm{N}$ bonds which are due to the tertiary amino group from aliphatic dendrimer structure are at $1230-1278 \mathrm{~cm}^{-1}$. The $\mathrm{C}-\mathrm{N}-\mathrm{C}$ stretch from the imidic 1,8-naphthalimide structure is at $1355-1384 \mathrm{~cm}^{-1}$.
The bands at $1538-1589 \mathrm{~cm}^{-1}$ are assigned to the aromatic $\mathrm{C}-\mathrm{C}$ stretching. The bending vibrations of $\mathrm{CH}_{2}$ groups from the aliphatic dendrimer structure give rise to bands at 1413$1428 \mathrm{~cm}^{-1}$. It should be stressed that in the Raman spectra vibrations of $\mathrm{C}=\mathrm{O}$ groups do not demonstrate intensive bands as observed in the infrared spectra. The band attributed to $\mathrm{C}=\mathrm{O}$ vibrations is detected with very small intensity near $1680 \mathrm{~cm}^{-1}$.

Interest was demonstrated to investigate the type of dendrimer generation on the position of the signals in Raman spectra. In Figure 5 the Raman spectra of $\mathrm{PPAl} / \mathrm{Cu}^{2+}$ and PPA2 $/ \mathrm{Cu}^{2+}$ complexes at $200-1800 \mathrm{~cm}^{-1}$ range are presented as an example. It is seen that both spectra are almost identical which is due to the similar polarization of the dendrimer molecules. This is a proof that the generation of the dendrimers does not affect their polarization. The determining factor in this process is the type of the fluorophore comprised in the dendrimer.

In summary, it has been demonstrated that the infrared and Raman spectroscopies can be used as complementary methods for structural analysis, identification, and characterization of modified with 1,8-naphthalimide units poly(propylene amine) dendrimers from first and second generations and their $\mathrm{Cu}^{2+}$ and $\mathrm{Zn}^{2+}$ complexes.

\section{Acknowledgment}

The authors wish to acknowledge the COST TD1102: photosynthetic proteins for technological applications: biosensors and biochips (PHOTOTECH).

\section{References}

[1] G. R. Newkome and C. D. Shreiner, "Poly(amidoamine), polypropylenimine, and related dendrimers and dendrons possessing different $1 \rightarrow 2$ branching motifs: an overview of the divergent procedures," Polymer, vol. 49, no. 1, pp. 1-173, 2008. 
[2] I. Grabchev, D. Staneva, and R. Betcheva, "Fluorescent dendrimers as sensors for biologically important metal cations," Current Medical Chemistry, vol. 19, no. 29, pp. 4976-4983, 2012.

[3] I. Grabchev, P. Bosch, M. McKenna, and A. Nedelcheva, "Synthesis and spectral properties of new green fluorescent poly(propyleneimine) dendrimers modified with 1,8naphthalimide as sensors for metal cations," Polymer, vol. 48, no. 23, pp. 6755-6762, 2007.

[4] I. Grabchev, S. Dumas, J. Chovelon, and A. Nedelcheva, "First generation poly(propyleneimine) dendrimers functionalised with 1,8-naphthalimide units as fluorescence sensors for metal cations and protons," Tetrahedron, vol. 64, no. 9, pp. 2113-2119, 2008.

[5] I. Grabchev, P. Bosch, M. McKenna, and D. Staneva, "A new colorimetric and fluorimetric sensor for metal cations based on poly(propilene amine) dendrimer modified with 1,8naphthalimide," Journal of Photochemistry and Photobiology A, vol. 201, no. 1, pp. 75-80, 2009.

[6] I. Grabchev, D. Staneva, and J. Chovelon, "Photophysical investigations on the sensor potential of novel, poly(propylenamine) dendrimers modified with 1,8-naphthalimide units," Dyes and Pigments, vol. 85, no. 3, pp. 189-193, 2010.

[7] I. Grabchev, D. Staneva, S. Dumas, and J. Chovelon, "Metal ions and protons sensing properties of new fluorescent 4$\mathrm{N}$-methylpiperazine-1,8-naphthalimide terminated poly(propyleneamine) dendrimer," Journal of Molecular Structure, vol. 999, no. 1-3, pp. 16-21, 2011.

[8] S. P. Gautam, A. K. Gupta, S. Agrawal, and S. Sureka, "Spectroscopic characterization of dendrimers," International Journal of Pharmacy and Pharmaceutical Sciences, vol. 4, no. 2, pp. 77-80, 2012.

[9] B. Nikoobakht and M. A. El-Sayed, "Surface-enhanced Raman scattering studies on aggregated gold nanorods," Journal of Physical Chemistry A, vol. 107, no. 18, pp. 3372-3378, 2003.

[10] L. Fabris, M. Dante, T. Nguyen, J. B.-H. Tok, and G. C. Bazan, "SERS aptatags: new responsive metallic nanostructures for heterogeneous protein detection by surface enhanced raman spectroscopy," Advanced Functional Materials, vol. 18, no. 17, pp. 2518-2525, 2008.

[11] D. Kim, W. L. Daniel, and C. A. Mirkin, "Microarray-based multiplexed scanometric immunoassay for protein cancer markers using gold nanoparticle probes," Analytical Chemistry, vol. 81, no. 21, pp. 9183-9187, 2009.

[12] A. Baran, A. Fiedler, H. Schulz, and M. Baranska, "In situ Raman and IR spectroscopic analysis of indigo dye," Analytical Methods, vol. 2, no. 9, pp. 1372-1376, 2010.

[13] M. S. Refat, I. M. El-Deen, I. Grabchev, Z. M. Anwer, and S. ElGhol, "Spectroscopic characterizations and biological studies on newly synthesized $\mathrm{Cu}^{2+}$ and $\mathrm{Zn}^{2+}$ complexes of first and second generation dendrimers," Spectrochimica A, vol. 72, no. 4, pp. 772-782, 2009.

[14] N. Leopold and B. Lendl, "A new method for fast preparation of highly surface-enhanced raman scattering (SERS) active silver colloids at room temperature by reduction of silver nitrate with hydroxylamine hydrochloride," Journal of Physical Chemistry B, vol. 107, no. 24, pp. 5723-5727, 2003.

[15] I. Grabchev, V. Bojinov, and C. Petkov, "Infrared absorption studies of some new 1,8-naphthalimides," Chemistry of Heterocyclic Compounds, vol. 39, no. 2, pp. 179-183, 2003.

[16] U. Tamer, I. H. BoyacI, E. Temur, A. Zengin, I. Dincer, and Y. Elerman, "Fabrication of magnetic gold nanorod particles for immunomagnetic separation and SERS application," Journal of Nanoparticle Research, vol. 13, no. 8, pp. 3167-3176, 2011.

[17] R. A. Alvarez-Puebla and L. M. Liz-MArzan, "SERS Detection of small inorganic m olecules and ions," Angewandte Chemie International Edition, vol. 51, no. 45, pp. 11214-11223, 2012. 

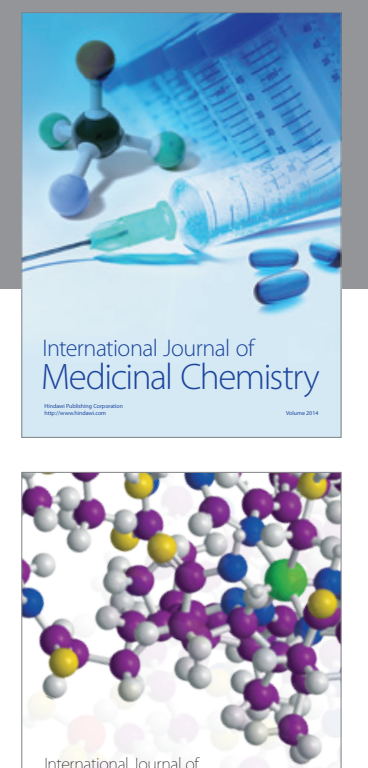

\section{Carbohydrate} Chemistry

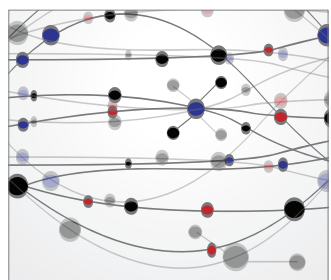

The Scientific World Journal
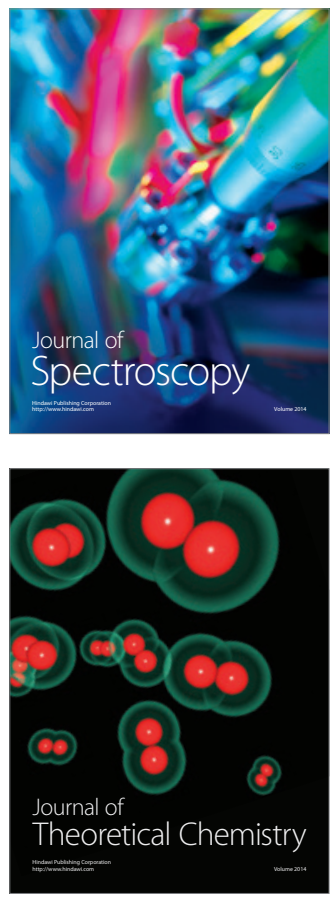
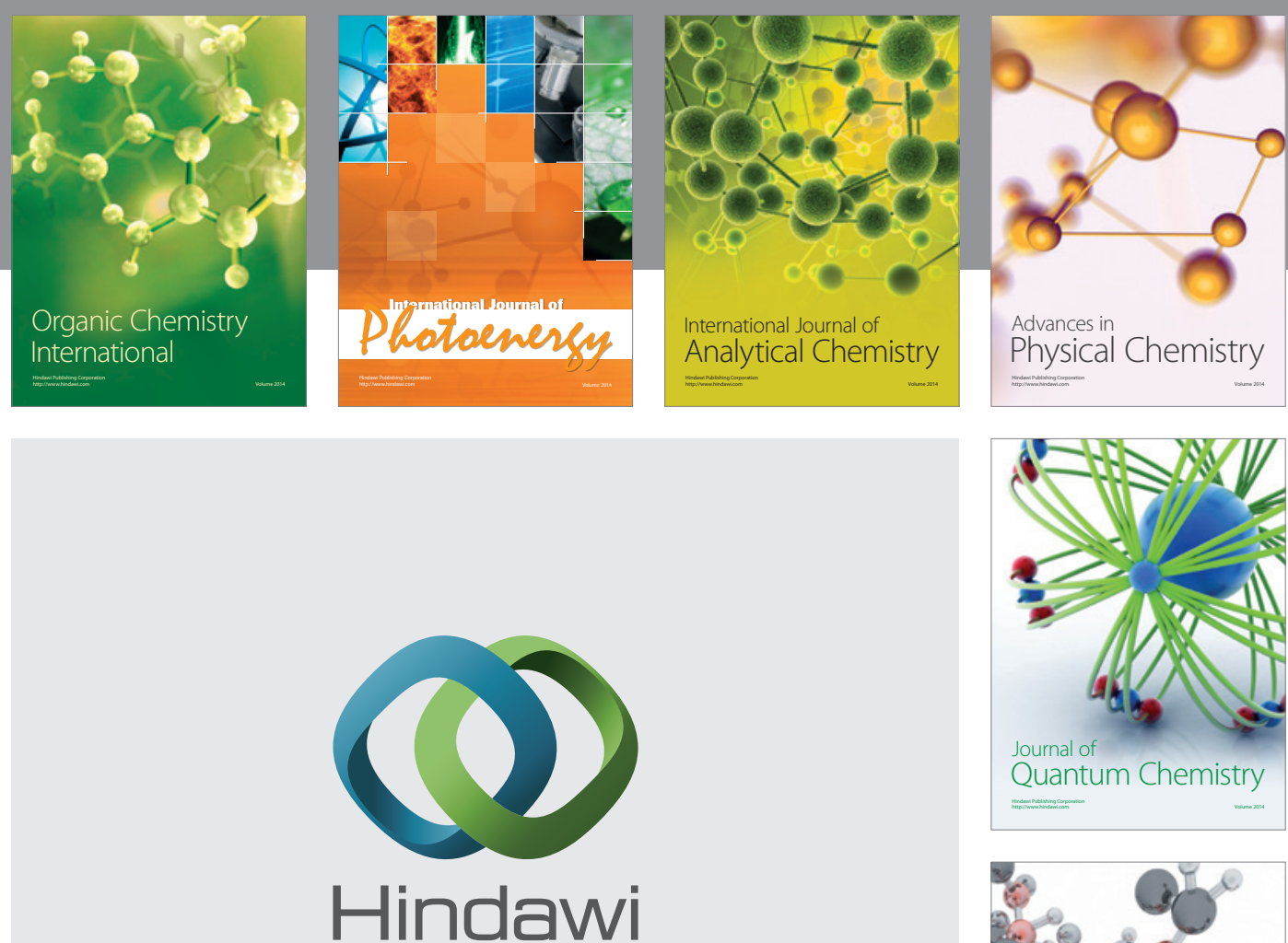

Submit your manuscripts at

http://www.hindawi.com

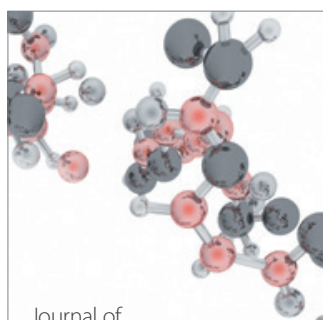

Analytical Methods

in Chemistry

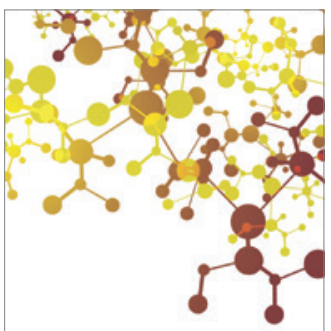

Journal of

Applied Chemistry

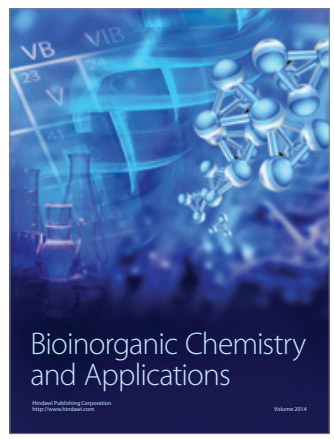

Inorganic Chemistry
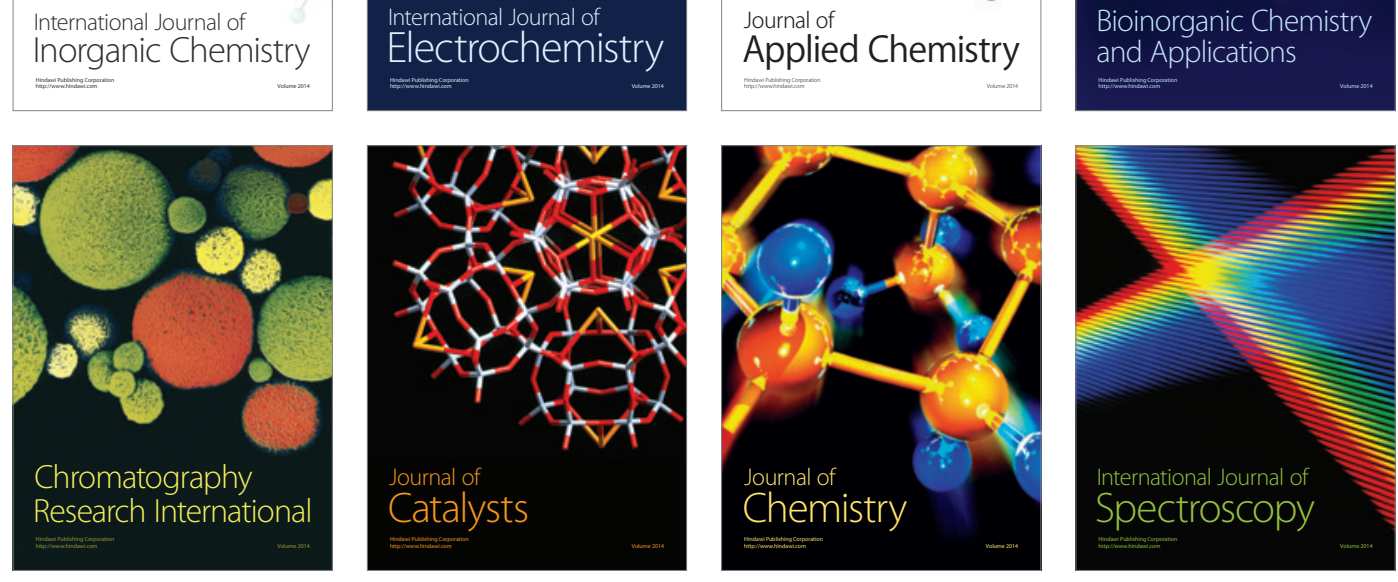